\title{
Expression of neuroepithelial transforming gene 1 is enhanced in oesophageal cancer and mediates an invasive tumour cell phenotype
}

Conor Lahiff ${ }^{*}$, Eoin Cotter ${ }^{2}$, Rory Casey ${ }^{3}$, Peter Doran ${ }^{1}$, Graham Pidgeon ${ }^{3}$, John Reynolds ${ }^{3}$, Padraic MacMathuna ${ }^{1}$ and David Murray ${ }^{2}$

\begin{abstract}
Introduction: Neuroepithelial Transforming Gene 1 (NET1) is a well characterised oncoprotein and a proven marker of an aggressive phenotype in a number of cancers, including gastric adenocarcinoma. We aimed to investigate whether NET1 plays a functional role in oesophageal cancer $(\mathrm{OAC})$ and its pre-malignant phenotype Barrett's oesophagus.

Methods: Baseline NET1 mRNA levels were determined by qPCR across a panel of six cell lines, including normal oesophageal, Barrett's and OAC derived cells. Quantification of NET1 protein in OAC cells was performed using Western blot and immunofluorescence. NET1 expression was modulated by treating with lysophosphatidic acid (LPA) and NET1-specific siRNA. The functional effects of NET1 knockdown were assessed in vitro using proliferation, migration and invasion assays.
\end{abstract}

Results: NET1 expression was increased in Barrett's and in OAC-derived cells in comparison to normal oesophageal cells. The highest expression was observed in OE33 a Barrett's-related OAC cell line. NET1 protein and mRNA expression was enhanced by LPA treatment in OAC and furthermore LPA treatment caused increased proliferation, migration and invasion in a NET1-dependent manner. NET1 knockdown resulted in reduced OAC cell proliferation and invasion.

Conclusions: As found in other malignancies, NET1 expression is elevated in OAC and its pre-malignant phenotype, Barrett's oesophagus. NET1 promotes OAC cell invasion and proliferation and it mediates LPA-induced OAC cell migration.

Keywords: Neuroepithelial transforming gene 1, NET1, Oesophageal cancer, Guanine nucleotide exchange factor, Gastrointestinal oncology

\section{Introduction}

Cancer of the oesophagus consists of two major histological subtypes - squamous cell carcinoma and adenocarcinoma. These clinically, biologically and morphologically distinct cancers, display different epidemiology and mandate different clinical approaches to their management. Adenocarcinoma occurs in the lower third of the oesophagus and oesophago-gastric junction and shares much in terms of phenotype with gastric cancer. Similar to gastric cancer, intestinal metaplasia can be a prominent precursor lesion in adenocarcinoma of the oesophagus [1,2]. This condition is known as Barrett's oesophagus. Barrett's can represent a pre-malignant stage for oesophageal cancer and can

\footnotetext{
*Correspondence: conorlahiff@physicians.ie

'Gastrointestinal Unit, Mater University Hospital, Dublin 7, Ireland Full list of author information is available at the end of the article
}

manifest as low risk (non dysplastic) lesions or higher risk lesions showing dysplasia histologically which can be low or high grade. Oesophageal cancer (OAC) usually presents late with symptoms such as dysphagia, weight loss, substernal pain or pressure or systemic symptoms and this is reflected by poor 5 year survival figures (less than $10 \%$ for patients with advanced disease [3]).

Neuroepithelial Transforming Gene 1 (NET1) is a guanine nucleotide exchange factor (GEF) which acts via activating RhoA [4]. Rho proteins belong to the Ras superfamily of GTPases and are involved in regulating the actin cytoskeleton, signal transduction and gene transcription. These molecules bring about their downstream effects by their GTPase activity, shuttling between an inactive GDP-bound and an active GTP-bound state. This cyclical activation/ inactivation brings about a conformational change with

\section{Ciomed Central}


resultant downstream effects involving a wide range of cellular processes, including cell motility [5]. Rho activation occurs in response to many cellular stimuli, including lysophosphatidic acid (LPA). LPA is a bioactive phospholipid and potent signalling molecule which acts through a family of $G$ protein coupled receptors [6]. It induces cellular proliferation through its receptors and activation of Rho. In our previous studies LPA activation of RhoA was shown to be mediated via NET1 in gastric cancer [4]. NET1 is involved in cytoskeletal organisation and cancer cell invasion [7-10]. Initially identified in a neuroepithelioma cell line, it is tumorigenic in nude mice [11]. In vitro studies have shown NET1 expression to drive invasion in gastric adenocarcinoma [12]. Separately it has also been shown to be functionally important in epithelial mesenchymal transition in retinal epithelial cells [13], keratinocytes [14] and during gastrulation [15]. NET1 has previously been shown to be differentially expressed and functionally important in mediating cancer cell invasion in gastric cancer $[12,16]$ and in squamous cell skin cancer (17). It has also been shown to be prominent in a number of other cancers [17-21] and to be a marker of poor prognosis in many of these (Table 1). Our group have previously shown NET1 to be of functional importance in breast and gastric cancer $[4,12,16,22]$. Recognising the mounting cellular and molecular evidence for a role for NET1 in mediating gastrointestinal (GI) cancers and coupled with the phenotypic similarities recognised in the pathogenesis of gastric and oesophageal adenocarcinomas [1], we sought to investigate and fully characterise the bioactivity of NET 1 in oesophageal cancer.

\section{Methods}

\section{Cell culture}

Our in vitro oesophageal cell line model consisted of six cell lines: Het1a an SV40 immortalised normal oesophageal cell line derived from a 25 year old male; two Barrett's cell lines QhTERT and GihTERT previously established by hTERT immortalisation (American Type Culture Collection, Virginia, USA) that represent non-dysplastic and high grade dysplastic Barrett's epithelium respectively; and three Barrett's related oesophageal adenocarcinoma cell lines - OE33, OE19 and JH-EsoAd1. OE33 was established from an adenocarcinoma of the lower esophagus of a 73-year-old female patient and is pathological stage IIA and poorly differentiated. OE19 is a pathological stage III moderately differentiated adenocarcinoma of gastric cardia/oesophageal gastric junction in a 72-year-old male patient. JH-EsoAD1 is from a patient with Barrett's associated adenocarcinoma [23]. AGS is a gastric cancer cell line from a 54 year old female and represents a moderate to poorly differentiated adenocarcinoma. SW480 is from a locally invasive (Duke's stage B) colon adenocarcinoma. QhTERT, GihTERT, OE33, OE19, Jh-EsoAd1, AGS and SW480 cells were cultured in RPMI 1640 medium containing $10 \%$ fetal calf serum, $2 \mathrm{mM}$ Glutamine and penicillin/streptomycin. Cells were cultured in T-75 flasks maintained at $37^{\circ} \mathrm{C}$ in a humidified atmosphere of $5 \%$ $\mathrm{CO}_{2}$. Het1a required a supporting layer composed of extracellular matrix proteins for subculture. Flasks were coated with $0.01 \mathrm{mg} / \mathrm{ml}$ bovine serum albumin, $0.01 \mathrm{mg} / \mathrm{ml}$ fibronectin and $0.03 \mathrm{mg} / \mathrm{ml}$ bovine type I collagen and were incubated overnight at $37^{\circ} \mathrm{C}$ in $5 \%$ $\mathrm{CO}_{2}$. Hetla was cultured in BEBM medium containing BPE $0.4 \%$, insulin $0.5 \mathrm{ml}$, hydrocortisone $0.5 \mathrm{ml}$, gentamicin/ amphotericin $0.5 \mathrm{ml}$, retinoic acid $0.5 \mathrm{ml}$, transferring $0.5 \mathrm{ml}$, triiodothyronine $0.5 \mathrm{ml}$, epinephrine $0.5 \mathrm{ml}$ and hEGF $0.5 \mathrm{ml}$ (Lonza Clonetics, Walkersville, USA). Flasks were maintained at $37^{\circ} \mathrm{C}$ in a humidified atmosphere of $5 \% \mathrm{CO}_{2}$.

\section{RNA extraction and qPCR}

RNA extraction was carried out using TRIzol ${ }^{\mathrm{Tm}}$ reagent (Sigma Aldrich, Ireland) under standard conditions. Quantitative PCR was carried out by the $\mathrm{SyBr}$ Green method using the Rotor-Gene $e^{\text {Tx }}$ 3000A Real Time Thermal Cycler and the Rotor-Gene ${ }^{\mathrm{ma}} 6$ software package. Specifically designed primers for NET-1 were purchased from Qiagen (Crawley, West Sussex, UK) and GAPDH was used as an endogenous control.

\section{Western blot}

Following LPA stimulation or siRNA treatment, cells were lysed and total protein was analysed by immublot using

Table 1 A summary of current data on NET1 in other human cancers

\begin{tabular}{lrr}
\hline Cancer type & Role of NET1 & Reference \\
\hline Gastric adenocarcinoma & Invasion via RhoA & Leyden et al. [12] \\
\cline { 2 - 3 } & & Murray et al. [4] \\
\hline Breast cancer & Predicts late stage and poor prognosis & Gilcrease et al. [18] \\
\cline { 2 - 3 } & Mediates morphine-induced cell migration in vitro & Ecimovic et al. [22] \\
\hline Glioma & Marker of invasion and aggressive disease. Poorer survival in NET1 positive & Tu et al. [20] \\
\hline Hepatocellular carcinoma & Correlates with higher histological grade & Chen et al. [17] \\
\hline Cervical carcinoma & Highly expressed in cervical epithelial neoplasia and in carcinoma & Wollscheid et al. [21] \\
\hline
\end{tabular}


SC-50392 (Santa Cruz, United States) NET1 specific rabbit IgG monoclonal antibody.

\section{Immuno-fluorescence}

$2 \times 10^{4}$ cells were seeded into 8 well chamber slides, treated with either NET-1 specific siRNA or scramble siRNA and incubated at $37^{\circ} \mathrm{C}$ for 24 hours with $5 \% \mathrm{CO}_{2}$. Immuno-fluorescence was measured using SC-81333 (Santa Cruz, United States) NET1 specific mouse IgG monoclonal antibody and a FITC labelled secondary antibody.

\section{Optimisation of LPA treatment by dose/response}

In order to determine optimal treatment conditions for LPA in OE33 and het1a cell lines a dose/response experiment was performed. Cells were treated with 1, 5, 10 and $20 \mu \mathrm{LPA}$ and. NET1 mRNA expression was quantified by qPCR and protein expression was examined by Western blot.

\section{Gene knockdown by siRNA}

Two siRNA duplexes were designed and synthesised for silencing NET1 (Qiagen Inc. CA, USA). The duplexes were termed: NET1-1 (sense, 5' - GGA GGA UGC UAU AUU GAU A-3'; antisense, 5' - UAU CAA UAU AGC AUC CUC C-3') and NET1-2 (sense, 5'- GGU GUG GAU UGA UUG GAA A- $3^{\prime}$; antisense, $5^{\prime}$ UUU CCA AUC AAU CCA CAC C-3'). A chemically synthesized non-silencing siRNA duplex (sense, 5'-UUC UCC GAA CGU GUC ACG U-3'; antisense, 5'-ACG UGA CAC GUU CGG AGA A-3') that had no known homology with any mammalian gene was used to control for nonspecific silencing events. $4 \times 10^{5}$ OE33 cells were added to each well of a 6-well plate containing $2 \mathrm{ml}$ growth media and were incubated under the standard conditions of $37^{\circ} \mathrm{C}$ and $5 \% \mathrm{CO}_{2}$ in a humid incubator for $24 \mathrm{hr}$. After $24 \mathrm{hrs}$ the siRNA-containing culture medium was aspirated and $1.9 \mathrm{ml}$ of new medium was added to each well. $1 \mu \mathrm{l}(0.3 \mu \mathrm{g}, 10 \mathrm{nM}), 5 \mu \mathrm{l}(1.5 \mu \mathrm{g}, 50 \mathrm{nM}), 17 \mu \mathrm{l}(5 \mu \mathrm{g}$, $170 \mathrm{nM})$ and $25 \mu \mathrm{l}(7.5 \mu \mathrm{g}, 250 \mathrm{nM})$ siRNA were added to serum-free RPMI medium and then diluted appropriately in serum-containing medium as per manufacturer's instructions. Each specific oligonucleotide (NET1-1 and NET1-2) was examined individually and together in the same solution. NET1 mRNA expression was quantified by qPCR and protein expression was examined by Western blot and immunofluorescence.

\section{Proliferation assay}

$20 \mu \mathrm{l}$ of MTS reagent was added to each well of a 96 well plate containing $2 \times 10^{4}$ cells. Treatments were as follows; 10nM scramble siRNA (control), 10nM NET1-1 siRNA, 10nM scramble siRNA $+5 \mu \mathrm{M}$ LPA and $10 \mathrm{nM}$ NET1-1 + $5 \mu \mathrm{M}$ LPA. After transfection with siRNA, cells were incubated for 24 hours. MTS was then added and the plate was incubated for 2 hours at $37^{\circ} \mathrm{C}$ and $5 \% \mathrm{CO}_{2}$ and absorbance at $492 \mathrm{~nm}$ was read using a microplate reader.

\section{Migration assay}

Wound healing migration assays were performed using plastic well inserts (Ibidi, Germany) in 24 well plates. $8 \times 10^{4}$ cells were seeded to each side of a plastic insert inside each well. The following day 10nM NET1-1 siRNA was added with $10 \mathrm{nM}$ scramble siRNA acting as a control. Cells were incubated under standard conditions for 24 hours to achieve knockdown of NET1. Inserts were then carefully removed from each well and cells were fed with regular growth medium without siRNA. Wells for LPA treatment were treated with $5 \mu \mathrm{M}$ in medium. Cells were observed until they had migrated but not long enough to allow full closure of the gap created by removal of the insert (3 hours). Cells were then fixed using 1:1 methanol acetone and stained with crystal violet. Each well was then photographed at 3 hours and measurements were taken for each condition at three points along the gap between mono-layers of cells. All treatment conditions were carried out in triplicate and averages were calculated and recorded as distance in number of pixels across the gap. Comparisons were made between the scramble siRNA and NET1 knockdown wells. Analysis calculated average migration distances using Image J software (http://rsb.info.nih.gov/ij/).

\section{In vitro invasion assay}

Biocoat Matrigel (BD Biosciences, United Kingdom) invasion chambers were used to investigate and compare the effect of NET1 downregulation on the in vitro invasion of OE33 cells. $1 \times 10^{5}$ cells were seeded to the upper chamber in serum-free medium. Culture medium containing $20 \%$ FBS was added to the outer chambers which acted as a chemo-attractant for the cells. The plates were then incubated for $24 \mathrm{hr}$ in a $5 \% \mathrm{CO}_{2}$ humidified $37^{\circ} \mathrm{C}$ incubator. Following incubation, the cells which had invaded the membrane were fixed and stained. The membrane was then removed and mounted on a slide for microscopic assessment. Invasive cells were visualised at 40X magnification and the number of cells in five random fields were counted and an average calculated for each condition.

\section{Statistics}

All experiments were carried out in triplicate unless otherwise stated in results section. Quantitative PCR analysis was by delta Ct method and GAPDH was used to normalise the data. Bivariate statistical analysis was carried out using the student's $t$-test with the level of statistical significance taken as $\mathrm{p}<0.05$. 
Table 2 NET-1 mRNA expression in Barrett's oesophagus and oesophageal cancer cell lines relative to het1a (normal) oesophageal cell line

\begin{tabular}{lccc}
\hline Cell line & Description & Mean NET1 expression & Standard deviation \\
\hline Het1a & Normal oesophagus & 1.0 & 0 \\
\hline QhTERT & Non-dysplastic Barretts epithelium & 54.8 & 65.5 \\
\hline GihTERT & Chigh grade dysplastic Barretts epithelium & 2.8 & 2.5 \\
\hline JH-EsoAd1 & OAC & 2.8 & 2.5 \\
\hline OE19 & Stage lla, poorly differentiated OAC & 61.5 & 30.3 \\
\hline OE33 & & 180.4 & 178.4 \\
\hline
\end{tabular}

Specific cell lines are as identified in methods section.

\section{Results}

NET1 Expression is upregulated in oesophageal cancer cells Relative NET1 mRNA expression across all six cell lines is shown in Table 2. Hetla (normal) cell line set at an arbitrary reference value of 1 . There is a marked higher level of expression in the OE33 cell line. Because of this high NET1 level we chose this cell line for further experiments to characterise the role of NET1 in oesophageal cancer. Looking at other in vitro GI cancer models (Additional file 1: Figure S1), the OE33 cell line had greater NET1
mRNA expression compared to gastric (AGS) and colorectal (SW480) adenocarcinoma models.

\section{NET1 MRNA expression is modulated by targeted siRNA} and LPA

Optimal NET1 gene knockdown conditions were determined by dose-response and time-course transfections in OE33 cells. The most effective knockdown (76\%) was observed at $10 \mathrm{nM}$ for 24 hours using NET1 duplex 1 , as shown in Figure 1A (0.24 vs. control, $\mathrm{p}=0.01)$. Similar

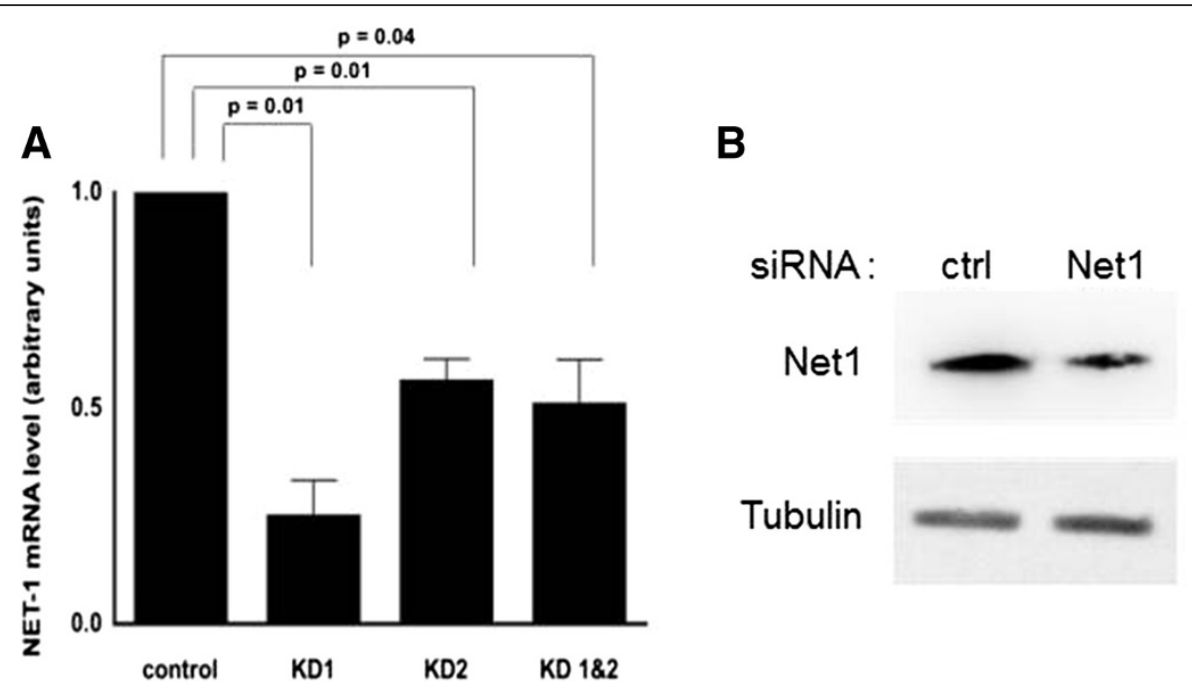

C

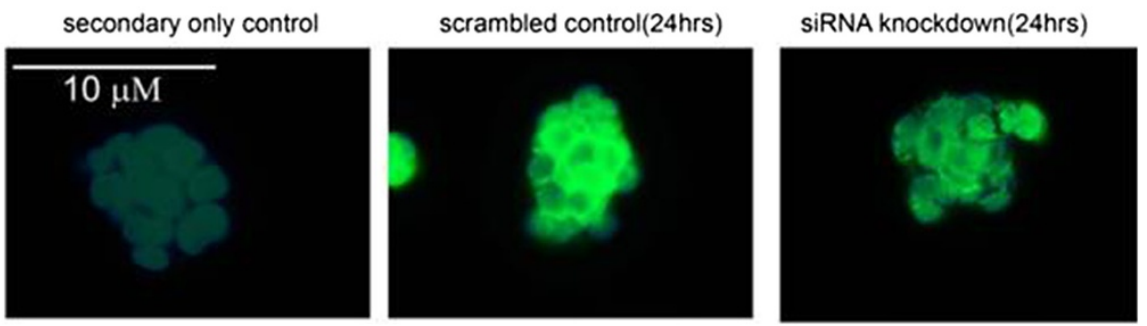

Figure 1 NET1 expression following knockdown by siRNA in OE33 cells. A) NET1 mRNA expression after gene knockdown with NET1-specific siRNA oligonucleotide 1 (KD1), NET1 siRNA oligonucleotide (KD2) and both siRNA in combination (KD 1\&2). B) Western blot showing NET1 protein expression in OE33 cells after gene knockdown, using tubulin expression as a control. Reduced expression was seen in NET1 knockdown compared to control. C) Immunofluorescence images from OE33 cells after siRNA NET1 gene knockdown. Reduced fluorescence was observed for NET1 knockdown compared to (scrambled) control siRNA at 24 hours incubation. Secondary antibody control image is included for reference. 


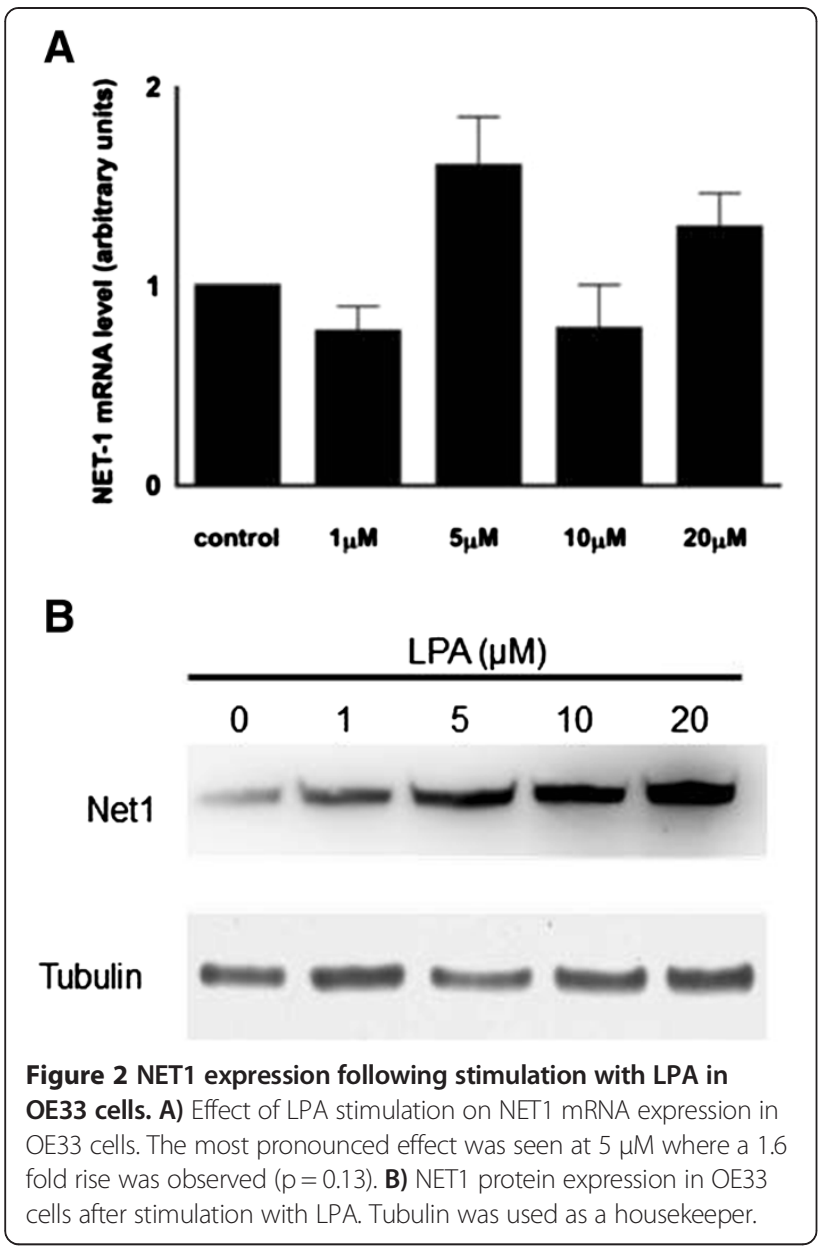

effects on NET1 protein expression were shown by Western blot and immunofluorescence (Figure $1 \mathrm{~B}$ and $\mathrm{C}$ ).

Maximum LPA effect (1.6 fold rise in NET1 mRNA, $\mathrm{p}=0.13)$ was seen at a treatment concentration of $5 \mu \mathrm{M}$ for 4 hours, as shown in Figure 2A. Consistent with this, LPA treatment was shown to result in elevated Net1 protein levels (Figure 2B).

\section{NET1 Knockdown reduces OAC cell proliferation}

NET1 gene knockdown reduced OE33 cell proliferation by $32 \%$ (mean absorbance 0.46 versus $0.68, \mathrm{p}=0.03$ ) in comparison to scramble siRNA control (Figure 3). Treatment with LPA had no significant effect on OAC cell proliferation. NET1 knockdown cells treated with LPA showed significantly reduced proliferation (39\% reduction, $\mathrm{p}=0.01)$ compared to control cells treated with LPA under the same conditions.

\section{NET1 Mediates LPA induced migration in OAC cells}

Figure 4 illustrates the effects of LPA treatment and NET1 knockdown on OAC cell migration, using gap width at time 0 as a reference. A higher level of migration was observed in LPA treated cells compared to non-targeting (NT) siRNA (control) cells (383.3 mean pixels versus 318.1 or $20 \%$ increase in migration, $p=0.01$ ). NET1 gene knockdown (KD) resulted in $25 \%$ reduction in migration (240 mean pixels versus 318.1, $\mathrm{p}=0.03$ ). NET1 knockdown cells treated with LPA had a $22 \%$ reduction in migration in comparison with control (NT + LPA), (298.5 versus 383.3 mean pixels, $\mathrm{p}=0.0003$ ).
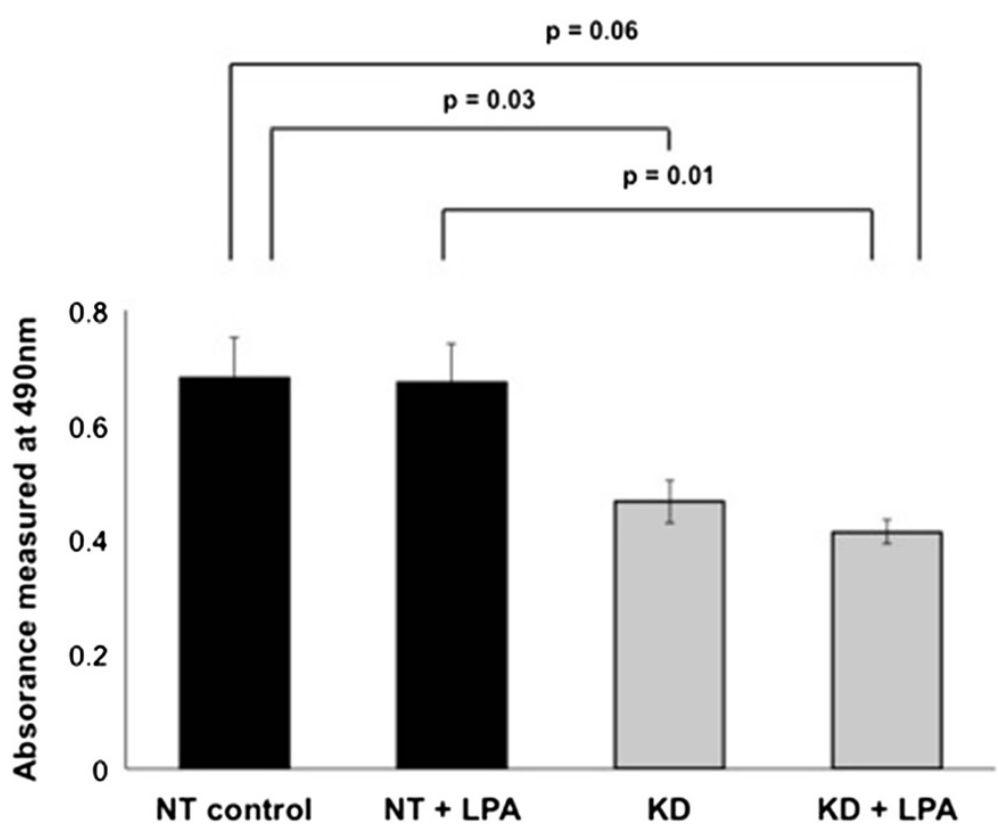

Figure 3 OE33 cell proliferation measured after NET1 knockdown (KD) and $5 \mu \mathrm{M}$ LPA stimulation compared with control (scramble siRNA) cells. Statistically significant differences are shown in bold. 


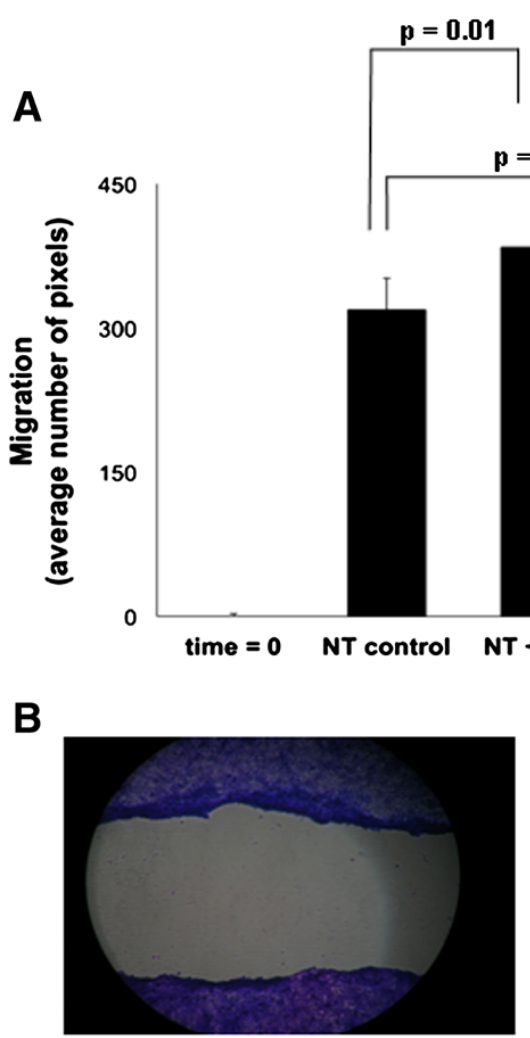

(a) scramble siRNA (control)

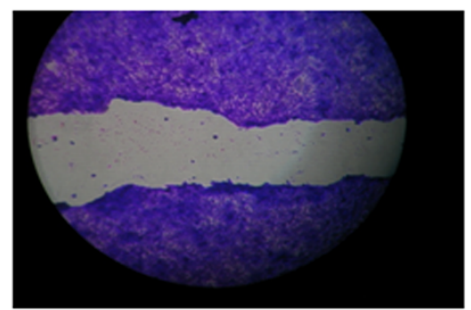

(c) scramble siRNA (control) + LPA

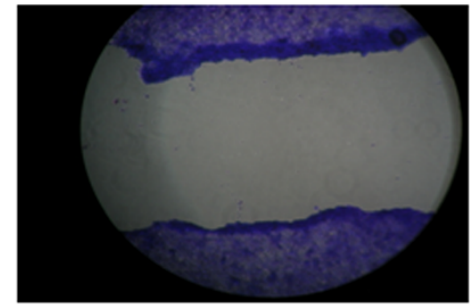

(b) NET-1 knockdown

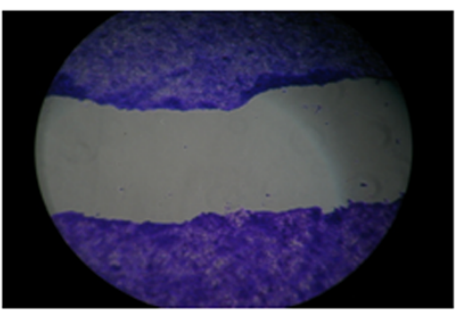

(d) NET-1 knockdown + LPA

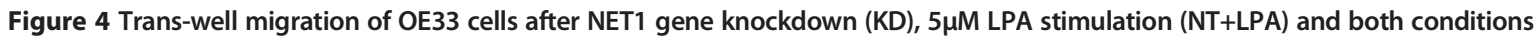
combined (KD+LPA). A) Migration across a gap is graphed by average number of pixels. Non-targeting siRNA (NT control) treated cells acted as a sham control for gene knockdown and time $=0$ is included as a reference. Statistically significant differences are shown in bold. B) Light microcopy images (10x magnification) of trans-well migration assay.

NET1 Promotes trans-membrane invasion in OAC cells NET1 knockdown cells were $45 \%$ less invasive at 24 hours than control cells, as shown in Figure 5 (56.8 versus 102.6 mean cells per high power field, $\mathrm{p}=0.04)$. Invasion was increased by $78 \%$ in control cells after $5 \mu \mathrm{M}$ LPA stimulation compared with NET1 knockdown cells (117.1 vs 66.1 mean cells per high power field, $\mathrm{p}=0.01$ ).

\section{Discussion}

The biological events in OAC carcinogenesis and metastasis are poorly understood. NET1 has been shown to be functionally important as a mediator of invasion and metastasis in gastric adenocarcinoma $[12,16]$ and is prognostically significant in other epithelial cancers $[18,20]$. We have demonstrated very high levels of NET1 expression in OAC and this strengthens our central hypothesis that this well characterised oncoprotein may be an important player in the molecular events leading to neoplastic progression in Barrett's and OAC. Analysis of baseline NET1 expression levels in our in vitro oesophageal model showed a progressive rise in expression from normal oesophagus to Barrett's to Barrett's related OAC. The higher expression of NET1 in OE33 OAC cells compared with the other two OAC cell lines may be a reflection of the poor level of differentiation these cells represent, and it has been shown elsewhere that NET1 is seen at 


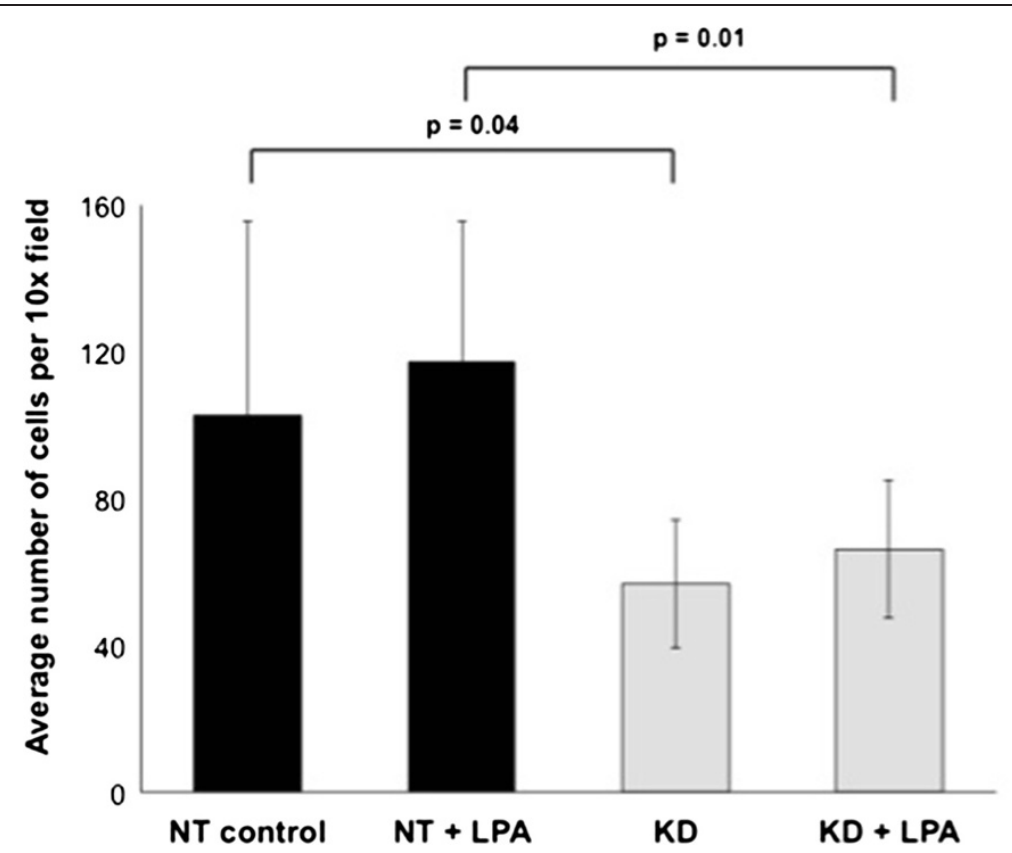

Figure 5 Trans-membrane invasion of OE33 cells after NET1 knockdown (KD) and 5 MM LPA stimulation (control + LPA) over 24 hours compared with control (NT/scramble siRNA). The final column represents both conditions combined (KD + LPA). Statistically significant differences are shown in bold.

high levels in the later metastatic stages of other cancers $[17,20]$. In a recent study (Lahiff et al 2013, under review British Journal of Cancer; Lahiff, et al. Gut 2012; 61: (Suppl 2) A255 (abstract); and Lahiff et al. Gastroenterology 2012; 142:5 (Suppl 1) S-531 (abstract)].) we have analysed the levels of NET1 mRNA in OAC tumor tissue. We showed that type I (Siewert classification) oesophagogastric junction (OGJ) adenocarcinomas expressed significantly higher levels of NET1, with lowest expression in type III and intermediate levels in type II $(\mathrm{p}=0.01)$. In patients with gastric and OGJ type III tumours, NET1 positive patients were more likely have advanced stage cancer $(p=0.03)$, had a higher number of transmural cancers $(p=0.006)$ and had a significantly higher median number of positive lymph nodes $(\mathrm{p}=0.03)$. In this subgroup, NET1 was associated with worse median overall (23 versus 15 months, $\mathrm{p}=0.02$ ) and disease free ( $36 \%$ versus $11 \%, \mathrm{p}=0.02$ ) survival.

In the current study, we investigated the role of NET1 in $\mathrm{OAC}$ by modulating its expression and investigating the effect on cell function. LPA stimulates invasion and migration in OE33 cells. We have previously shown that LPA, a phospholipid which acts through G protein coupled receptors and is known to activate RhoA, promotes gastric cancer cell invasion via NET1 [4]. In this current study we have shown that not only does LPA drive NET1 expression in OAC but that the functional effects of LPA stimulation in these cells are NET1 dependent. Although not explored in the current study, our ongoing efforts will define whether LPA drives RhoA activation in OAC cells as it does in gastric cancer cells. The mechanism by which LPA induces transcription of NET1 in OAC cells remains to be elucidated. We also previously reported LPA to drive the expression of NET1 mRNA in gastric cancer cells [4]. Likewise, we previous showed [16] that stimulation of gastric cancer cells with LPA resulted in the differential expression of over 2000 genes. Further work will elucidate the mechanism via which LPA induces NET1 mRNA transcription in OAC cells.

The results of the functional in vitro experiments presented here are broadly consistent across proliferation, migration and trans-membrane invasion assays. NET1 knockdown significantly reduced OE33 cancer cell proliferation, migration and invasion. LPA, a recognised mitogen, had no effect on proliferation in these OAC cells. However, when we examine the effect of LPA on scramble siRNA control cells compared with its effect after NET1 knockdown there was significant differences in proliferation, migration and invasion. While these results suggest the effect of LPA in promoting proliferation, migration and invasion in OAC may be NET1 dependent this needs to be qualified by the fact that in control cells at baseline we only observed a significant effect after LPA treatments in the migration assay. Furthermore, although not performed in this study, it would also be valuable to monitor the effect of NET1 overexpression in OAC cells and efforts, aimed at performing these analyses are currently ongoing. 
Epithelial Mesenchymal Transition (EMT) plays a key role in the metastasis of epithelial cancers through the involvement of various intracellular signalling pathways [24-26]. Loss of E-Cadherin is associated with EMT and tumour invasion [27] and has been linked functionally to NET1 and TGF $\beta$ [14]. Oesophageal cancer frequently exhibits loss of E cadherin and TGF $\beta$ receptors [28]. Interestingly RhoA, which our group have previously shown to be regulated by NET1 in gastric cancer [4], has also been shown to activate TGF $\beta$ [29]. Furthermore, we have previously shown NET1 expression to be required for the expression of TGF $\beta \mathrm{i}$, a key member of the TGF signalling pathway [16]. TGF $\beta$ is known to induce NET1 expression and in turn RhoA activation and reorganisation of the cytoskeletal via the Smad3 transcription factor [13]. The putative role of NET1 in epithelial mesenchymal transition via TGF- $\beta[13,14,19,30]$ and the significance of this concept in OAC, coupled with the data presented here, strengthen the hypothesis that NET1 plays an important role in the tumour biology of oesophageal adenocarcinoma.

\section{Conclusions}

The data presented from this study demonstrates that NET1, a recognised pro-invasive oncoprotein associated with aggressive gastrointestinal and non-gastrointestinal cancers is highly expressed and functionally active in OAC. In aggregate our data provides strong evidence that NET1 is biologically active in OAC and may be an important factor in promoting an aggressive tumour cell phenotype.

\section{Additional file}

Additional file 1: Figure S1. NET1 mRNA expression in other in vitro GI cancer models. OE33 cells line had highest expression of NET1 mRNA expression compared to gastric (AGS) and colorectal (SW480) adenocarcinoma models.

\section{Abbreviations}

NET1: Neuroepithelial transforming gene 1; OAC: Oesophageal cancer; Gl: Gastrointestinal; GEF: Guanine nucleotide exchange factor; LPA: Lysophosphatidic acid; EMT: Epithelial mesenchymal transition.

\section{Competing interests}

The authors declare that they have no competing interests.

\section{Authors' contributions}

CL: study concept and design, experimental work and acquisition of data, drafting of the manuscript, analysis and interpretation of data, critical revision of the manuscript for important intellectual content. EC, RC, GP: experimental work and acquisition of data, interpretation of data, critical revision of the manuscript for important intellectual content of the manuscript. PD, JR: analysis and interpretation of data, drafting of the manuscript critical revision of the manuscript for important intellectual content of the manuscript. PMM: study concept and design, analysis and interpretation of data, critical revision of the manuscript for important intellectual content of the manuscript. DM: study concept and design, experimental work and acquisition of data, critical revision of the manuscript for important intellectual content of the manuscript. All authors read and approved the final manuscript.

\section{Funding source}

The Mater Foundation.

\section{Author details}

${ }^{1}$ Gastrointestinal Unit, Mater University Hospital, Dublin 7, Ireland. ${ }^{2}$ University College Dublin Clinical Research Centre, University College Dublin School of Medicine and Medical Science, Dublin 4, Ireland. ${ }^{3}$ Department of Surgery, St. James's Hospital and Trinity College Dublin, Dublin 8, Ireland.

Received: 14 April 2013 Accepted: 3 August 2013

Published: 14 August 2013

\section{References}

1. Correa P, Piazuelo MB, Wilson KT: Pathology of gastric intestinal metaplasia: clinical implications. Am J Gastroenterol 2010, 105:493-498.

2. Odze RD: Update on the diagnosis and treatment of Barrett esophagus and related neoplastic precursor lesions. Arch Pathol Lab Med 2008, 132:1577-1585.

3. Gertler R, Stein HJ, Langer R, et al: Long-term outcome of 2920 patients with cancers of the esophagus and esophagogastric junction: evaluation of the New Union Internationale Contre le Cancer/American Joint Cancer Committee staging system. Ann Surg 2011, 253:689-698.

4. Murray D, Horgan G, Macmathuna P, et al: NET1-mediated RhoA activation facilitates lysophosphatidic acid-induced cell migration and invasion in gastric cancer. Br J Canc 2008, 99:1322-1329.

5. Boguski MS, McCormick F: Proteins regulating Ras and its relatives. Nature 1993, 366:643-654.

6. Dorsam RT, Gutkind JS: G-protein-coupled receptors and cancer. Nature reviews. Cancer 2007, 7:79-94.

7. Alberts AS, Geneste O, Treisman R: Activation of SRF-regulated chromosomal templates by Rho-family GTPases requires a signal that also induces H4 hyperacetylation. Cell 1998, 92:475-487.

8. Garcia-Mata R, Dubash AD, Sharek $L$, et al: The nuclear RhoA exchange factor Net1 interacts with proteins of the Dlg family, affects their localization, and influences their tumor suppressor activity. Mol Cell Biol 2007, 27:8683-8697.

9. Qin H, Carr HS, Wu X, et al: Characterization of the biochemical and transforming properties of the neuroepithelial transforming protein 1. $J$ Biol Chem 2005, 280:7603-7613.

10. Schmidt A, Hall A: The Rho exchange factor Net1 is regulated by nuclear sequestration. J Biol Chem 2002, 277:14581-14588.

11. Chan AM, Takai S, Yamada K, et al: Isolation of a novel oncogene, NET1, from neuroepithelioma cells by expression cDNA cloning. Oncogene 1996, 12:1259-1266.

12. Leyden J, Murray D, Moss A, et al: Net1 and Myeov: computationally identified mediators of gastric cancer. Br J Canc 2006, 94:1204-1212.

13. Lee J, Moon HJ, Lee JM, et al: Smad3 regulates Rho signaling via NET1 in the transforming growth factor-beta-induced epithelial-mesenchymal transition of human retinal pigment epithelial cells. J Biol Chem 2010, 285:26618-26627.

14. Papadimitriou $E$, Vasilaki $E$, Vorvis $C$, et al: Differential regulation of the two RhoA-specific GEF isoforms Net1/Net1A by TGF-beta and miR-24: role in epithelial-to-mesenchymal transition. Oncogene 2011, 7;31(23):2862-2875.

15. Miyakoshi A, Ueno N, Kinoshita N: Rho guanine nucleotide exchange factor xNET1 implicated in gastrulation movements during Xenopus development. Differ Res Biol Divers 2004, 72:48-55.

16. Bennett G, Sadlier D, Doran PP, et al: A functional and transcriptomic analysis of NET1 bioactivity in gastric cancer. BMC Canc 2011, 11:50.

17. Chen L, Wang Z, Zhan X, et al: Association of NET-1 gene expression with human hepatocellular carcinoma. Int J Surg Pathol 2007, 15:346-353.

18. Gilcrease MZ, Kilpatrick SK, Woodward WA, et al: Coexpression of alpha6beta4 integrin and guanine nucleotide exchange factor Net1 identifies node-positive breast cancer patients at high risk for distant metastasis. Canc Epidemiol Biomarkers Prev Publ Am Assoc Canc Res Cosponsored Am Soc Prev Oncol 2009, 18:80-86.

19. Shen SQ, Li K, Zhu N, et al: Expression and clinical significance of NET-1 and PCNA in hepatocellular carcinoma. Med Oncol 2008, 25:341-345.

20. Tu Y, Lu J, Fu J, et al: Over-expression of neuroepithelial-transforming protein 1 confers poor prognosis of patients with gliomas. Jpn J Clin Oncol 2010, 40:388-394. 
21. Wollscheid V, Kuhne-Heid R, Stein I, et al: Identification of a new proliferation-associated protein NET-1/C4.8 characteristic for a subset of high-grade cervical intraepithelial neoplasia and cervical carcinomas. International journal of cancer. J Int Canc 2002, 99:771-775.

22. Ecimovic $P$, Murray $D$, Doran $P$, et al: Direct effect of morphine on breast cancer cell function in vitro: role of the NET1 gene. Br J Anaesth 2011, 107(6):916-923.

23. Rockett JC, Larkin K, Darnton SJ, et al: Five newly established oesophageal carcinoma cell lines: phenotypic and immunological characterization. Br J Canc 1997, 75:258-263.

24. Abdel-Latif MM, O'Riordan J, Windle HJ, et al: NF-kappaB activation in esophageal adenocarcinoma: relationship to Barrett's metaplasia, survival, and response to neoadjuvant chemoradiotherapy. Ann Surg 2004, 239:491-500.

25. Kang Y, Massague J: Epithelial-mesenchymal transitions: twist in development and metastasis. Cell 2004, 118:277-279.

26. Thiery JP, Morgan M: Breast cancer progression with a Twist. Nat Med 2004, 10:777-778.

27. Yang J, Mani SA, Donaher $\mathrm{JL}$, et al: Twist, a master regulator of morphogenesis, plays an essential role in tumor metastasis. Cell 2004, 117:927-939.

28. Andl $C D, M c C o w a n ~ K M$, Allison $G L$, et al: Cathepsin $B$ is the driving force of esophageal cell invasion in a fibroblast-dependent manner. Neoplasia 2010, 12:485-498.

29. Bhowmick NA, Ghiassi M, Bakin A, et al: Transforming growth factor-beta1 mediates epithelial to mesenchymal transdifferentiation through a RhoA-dependent mechanism. Mol Biol Cell 2001, 12:27-36.

30. Nakaya Y, Sukowati EW, Wu Y, et al: RhoA and microtubule dynamics control cell- basement membrane interaction in EMT during gastrulation. Nat Cell Biol 2008, 10:765-775.

doi:10.1186/1756-9966-32-55

Cite this article as: Lahiff et al: Expression of neuroepithelial transforming gene 1 is enhanced in oesophageal cancer and mediates an invasive tumour cell phenotype. Journal of Experimental \& Clinical Cancer Research 2013 32:55.

\section{Submit your next manuscript to BioMed Central and take full advantage of:}

- Convenient online submission

- Thorough peer review

- No space constraints or color figure charges

- Immediate publication on acceptance

- Inclusion in PubMed, CAS, Scopus and Google Scholar

- Research which is freely available for redistribution 